\title{
Pemanfaatan Krisna Funtastic Land Sebagai Sarana Leisure And Recreation Di Desa Temukus Kabupaten Buleleng
}

Nyoman Ega Ismana a, 1, Gede Indra Bhaskara a, 2

1ismanaega@yahoo.com,2gbhaskara@unud.ac.id

a Program Studi Sarjana Destinasi Pariwisata, Fakultas Pariwisata,Universitas Udayana, Jl. Dr. R. Goris, Denpasar, Bali 80232 Indonesia

\begin{abstract}
The development of tourism in Bali to date has had a positive impact on the economy of the community. In addition, tourism can increase foreign exchange and provide employment.This study contains what motivation and how the characteristics of visitors Krisna Funtastic Land and how appropriate utilization in Krisna Funtastic Land in Leisure and Recreation activities.

The data used in this study are qualitative data in the form of Krisna Funtastic Land, the state of facilities and infrastructure, the history of Krishna Funtastic Land and the utilization of visitors.

The result show that the characteristics of visitors who come to Krisna Funtastic Land based on age are the majority> 20 years old, based on the area of origin originating from the Regency of Buleleng, especially the City of Singaraja, based on female sex. Based on the level of education having a high school / vocational education level, based on the type of occupation the majority are still students, based on the source of information getting information comes from friends / relations. For the appropriate utilization in Krisna Funtastic Land based on the motivation and characteristics of visitors Krisna Funtastic Land which is one of the tourist attractions in Krisna Funtastic Land, so the manager should add the game rides not only focus for children, but also for adults, The type of game rides should more be reproduced to increase the interest of tourists to visit.
\end{abstract}

Keywords: Utilization, motivation and characteristics

\section{PENDAHULUAN}

Perkembangan pariwisata di Bali sampai saat ini sudah memberikan dampak positif bagi perekonomian masyarakat. Selain itu pariwisata dapat meningkatkan devisa negara dan memberikan lapangan kerja. Hal tersebut terjadi karena upaya pembangunan pariwisata secara berimbang dan juga berkelanjutan. Pariwisata adalah perpaduan dari beberapa aspek-aspek diantaranya adalah entertainment, dan pariwisata merupakan pelaksanaan dari rekreasi.

Leisure and Recreation adalah salah satu aspek pariwisata yang menyangkut aktivitas manusia yang dilakukan pada waktu senggang dan merupakan kebutuhan manusia yang bersifat universal dan fundamental untuk memperoleh kepuasan. Krisna Funtastic Land merupakan salah satu objek wisata yang terletak di Jl Raya Seririt, desa Temukus, kecamatan Banjar, kabupaten Buleleng, Bali. Tempat wisata ini berada di daerah persawahan, dekat dengan pantai, sehingga tepat apabila dikembangkan sebagai pemenuhan kebutuhan Leisure and Recreation.
Kabupaten Buleleng yang merupakan salah satu kabupaten di provinsi Bali dengan ibu kota kabupaten Kota Singaraja. Kabupaten buleleng memiliki garis pantai membentang sepanjang dari sebelah timur perbatasan karangasem sampai ujung barat perbatasan Jembrana, hal tersebut selain memiliki potensi hasil perikanan juga membuat kabupaten ini menawarkan potensi wisata pantai yang indah dan menarik dan sudah terkenal luas bukan hanya dalam negeri saja namun sudah sampai mancanegara. Selain sebagai penghasil pertanian terbesar di Bali (terkenal dengan produksi buah salak bali dan buah jeruk keprok Tejakula), Kabupaten Buleleng juga memiliki objek pariwisata yang cukup banyak seperti Pantai Lovina, Pantai Pemuteran, Pura Pulaki, Pulau Menjangan, Air Sanih, Pemandian Air Panas Banjar, Danau Beratan, Twin Lake yaitu Danau Buyan dan Tamblingan dan tentunya kota Singaraja sendiri.

Tepat pada 11 November 2016 yang lalu, tempat rekreasi di Bali ini sudah resmi dibuka untuk umum dan sangat ramai sekali dikunjungi oleh para wisatawan, terutama wisatawan lokal. Keberaaan wahana permainan ini berdekatan 
dengan Krisna Oleh-Oleh, tepatnya berada di bagian belakangnya. Ditambah lagi, tempat ini sejatinya masih sama-sama dalam satu grup dengan Krisna Oleh-Oleh yang tergabung dalam Krisna Group. Perjalanan Dari Denpasar Menuju ke Krisna Funtastic Land ini tidak terlalu sulit. Pengunjung bisa menjangkau tempat ini dengan durasi perjalanan kurang lebih dua jam. Bisa dilakukan dengan memanfaatkan sarana sewa kendaraan bermotor yang bisa dijumpai dengan mudah di Bali.

Berdasarkan uraian diatas maka rumusan masalah artikel ini adalah bagaimana motivasi dan karakteristik pengunjung di Krisna Funtastic Land dan bagaimana pemanfaatan Krisna Funtastic Land sebagai sarana rekreasi di Desa Temukus Kabupaten Buleleng. Tujuan artikel ini untuk mengetahui karakteristik, motivasi pengunjung dan pemanfaatan di Krisna Funtastic Land sebagai sarana rekreasi di Desa Temukus Kabupaten Buleleng.

\section{TINJAUAN PUSTAKA}

\subsection{Telaah Hasil Penelitian Sebelumnya}

Penelitian pertama jurnal dari

Permatasari (2018) yang berjudul "Studi Komparasi Taman Kota Lumintang Dan Taman Kota Puputan Margarana Niti Mandala Renon Sebagai Sarana Leisure And Recreation". Peneliti disini menguraikan tentang bagaimana Komparasi fasilitas Taman Kota Lumintang dan Taman Kota Puputan Margarana Niti Mandala Renon sebagai sarana leisure and recreation.

Penelitian lain laporan wisata karya III dari Vina (2008) tentang Pemanfaatan Atlanta Waterpark and Playground Sebagai Sarana Leisure and Recreation di kabupaten Banyuwangi Provinsi Jawa Timur. Penelitian ini menguraikan tentang bagaimana pemanfaatan dan makna rekreasi yang telah dilakukan oleh pengunjung di Atlanta Waterpark and Playground dalam aktivitas Leisure and Recreation.

\subsection{Landasan Konsep dan Teori Analisis}

Adapun konsep yang digunakan dalam artikel ini, yaitu :

1. Konsep Pemanfaatan

Pemanfaatan mengandung arti mendayagunakan suatu objek sehingga memiliki suatu arti hal, cara, hasil kerja atau sebuah proses yang dilakukan dalam bentuk hasil perbuatan dalam memanfaatkan sesuatu yang dilakukan oleh orang perorangan. (Arifin, 2005)

2. Konsep Leisure

Leisure adalah sisa waktu selain kegiatan rutin sehari-hari seperti kegiatan kerja, belajar, urusan rumah tangga, dan lain sebagainya (Marpaung, 2000)

3. Konsep Rekreasi

Rekreasi merupakan aktivitas yang bersifat fisik, mental, emosional dan social dengan terdorong oleh suatu keinginan atau motif yaitu bebas dalam memanfaatkan waktu luang dengan tanpa adanya paksaan. (Arifin, 2005)

4. Konsep Makna Rekreasi

makna rekreasi adalah sebagai kebutuhan fundamental, makna rekreasi dan pendidikan, makna rekreasi dan kesehatan, makna rekreasi dan character building (pembangunan jiwa seseorang), makna rekreasi dan pencegahan kriminalitas, makna rekreasi dan moral dan makna rekreasi ekonomi. (Haryono, 1978)

5. Konsep Motivasi

Menurut Mc. Donald (2007), menyebutkan bahwa motivasi sebagai perubahan energi dalam diri seseorang yang ditandai dengan munculnya "feeling" dan didahului dengan tanggapan terhadap adanya tujuan.

\section{METODE PENELITIAN}

Penelitian ini dilakukan di Krisna Funtastic Land yang berada di desa Temukus, Kecamatan Buleleng, Kabupaten Buleleng, Provinsi Bali. Ruang lingkup dalam penelitian ini, yaitu motivasi dan karakteristik wisatawan yang berkunjung ke Krisna Funtastic Land dan pemanfaatan yang dilakukan pengunjung dalam mengisi waktu luang di Krisna Funtastic Land. Jenis data yang digunakan, data kualitatif (Sugiarto,2000), dan kuantitatif (Kusmayadi dan Sugiarto, 2000). Sumber data yang digunakan, yaitu data primer dan data sekunder. (Sugiyono,2014) Teknik pengumpulan data yang 
digunakan yaitu observasi (Cresswell,2014) wawancara (Sutopo,2006) dan dokumentasi (Sugiyono,2009) Kuisioner dalam penelitian ini mengambil jumlah sampel sebanyak 80 responden dengan menggunakan teknik pengambilan sampel, yaitu accidental sampling. Untuk menentukan informan menggunakan teknik purposive sampling. Untuk data yang telah diperoleh dari 80 responden dianalisis menggunakan teknik analisis statistik deskriptif (Santoso,2014) Teknik analisis data dalam penlitian ini menggunakan teknik analisis data deskriptif kualitatif yaitu dilakukan dengan langkah bekerja dengan data, mengorganisasikan data, mencari dan menemukan pola, menemukan apa yang penting dan apa yang dipelajari, serta memutuskan apa yang dapat diceritakan kepada orang lain berdasarkan data yang didapatkan (Moleong, 2012).

\section{HASIL DAN PEMBAHASAN}

Krisna Funtastic Land daya tarik wisata yang berada di Desa Temukus, Kecamatan Banjar, Kabupaten Buleleng, Provinsi Bali. Lokasi penelitian ini terletak $86 \mathrm{~km}$ dari kota Denpasar, dimana lokasi Krisna Funtastic Land ini keberadaanya di kelilingi oleh persawahan penduduk dan dekat juga dengan pantai, sehingga pengunjung yang datang ke sana akan disambut dengan hijaunya persawahan yang indah. Krisna Funtastic Land merupakan objek wisata baru dan satu-satunya tempat wahana permainan pertama yang terbesar di kabupaten Buleleng yang didirikan oleh Gusti Ngurah Berlin Brahmantara yang tinggal di Denpasar. Gusti Ngurah Berlin Brahmantara adalah anak pertama dari pemilik Krisna Oleh-oleh yang bernama Gusti Ngurah Anom atau sering disapa dengan nama Ajik Cok.

Krisna Funtastic Land di bangun di tanah yang seluas kurang lebih sekitar 5 hektar yang dulunya tanah tersebut merupakan persawahan masyarakat setempat. Pihak pengelola ingin membuat tempat wisata Krisna Funtastic land di kabupaten Buleleng tempatnya di desa Temukus karena beliau ingin lebih memajukan pariwisata di Buleleng. Faktor lainnya karena desa Temukus merupakan lokasi yang sangat bagus untuk membuat objek wisata. Disamping itu juga di desa Temukus terdapat pemandangan yang indah seperti persawahan dan juga di bagian utara terdapat pantai. Krisna Funtastic land mulai dibangun pada bulan Juni 2016 dan pada bulan November 2016 pengerjaannya masih belum selesai secara tuntas.

Mendekati akhir tahun yang tentunya banyak keluarga yang memanfaatkan waktu luangnya untuk rekreasi, maka pada tanggal 9 November 2016 diadakanlah grand opening yang bintang tamunya adalah Agnes Monica. Setelah grand opening tersebut maka pada tanggal 11 November 2016 Krisna Funtastic land dibuka secara resmi untuk pengunjung, walaupun masih ada beberapa wahana yang belum selesai dibuat. Di Krisna Funtastic land terdapat 16 wahana yang siap memanjakan para pengunjung diantaranya ada Airbone Shot, Boom-Boom Cars, Carousel, Control Plane, Flying Cakra, Singaraja Flyer dan masih banyak lagi. Namun ada dua wahana yang belum selesai dibuat dan masih dalam proses pembuatan, diantaranya Rumah Kaca dan Inflatable Castle.

\subsection{Motivasi dan karakteristik pengunjung}

Motivasi Pengunjung Krisna Funtastic Land Motivasi wisatawan yang berkunjung ke Krisna Funtastic Land dalam penelitian ini akan diklasifikasikan menjadi lima motivasi yaitu :

1. Motivasi untuk berekreasi

2. Motivasi bersenang-senang/tamasya

3. Motivasi untuk menyalurkan hobi

4. Motivasi bertemu orang baru

5. Motivasi kesehatan

Motivasi Pengunjung Krisna Funtastic Land diketahui bahwa pengunjung yang mempunyai motivasi untuk berekreasi sebanyak 64 orang (80\%). Pengunjung yang memiliki motivasi bersenang-senang sebanyak 16 orang (20\%).

Karakteristik Pengunjung yang datang ke Krisna Funtastic Land diuraikan seperti dibawah ini :

a. Karakteristik Pengunjung Krisna Funtastic Land berdasarkan Umur diketahui kelompok umur kurang dari 20 tahun adalah kelompok umur terbanyak yang melakukan kunjungan ke Krisna Funtastic Land.

b. Karakteristik Pengunjung Krisna Funtastic Land Berdasarkan Daerah Asal bahwa 
pengunjung yang berkunjung ke Krisna Funtastic Land kebanyakan dari Singaraja yaitu sebanyak 70 orang (87.5\%).

c. Karakteristik Pengunjung Krisna Funtastic Land berdasarkan Tingkat Pendidikan bahwa pengunjung yang tingkat pendidikannya SMA adalah yang paling terbanyak yang berkunjung ke Krisna Funtastic Land dengan jumlah 45 orang (56.3\%).

d. Karakteristik Pengunjung Krisna Funtastic Land Berdasarkan Jenis Pekerjaan diketahui bahwa pengunjung yang berprofesi sebagai karyawan swasta sebanyak 5 orang $(6,3 \%)$, PNS sebanyak 10 orang $(12,5 \%)$, ibu rumah tangga sebanyak 3 orang $(3,8 \%)$, mahasiswa sebanyak 24 orang $(30 \%)$. Sedangkan pelajar menduduki posisi yang paling tinggi sebanyak 36 orang $(40 \%)$, dan terakhir buruh/petani hanya 2 orang $(2,5 \%)$.

e. Karakteristik Pengunjung Krisna Funtastic Land Berdasarkan Asal Sumber Informasi diketaui bahwa sebagian besar dari pengunjung yang berkunjung ke Krisna Funtastic Land mengetahui objek ini berdasarkan informasi dari teman/relasi mereka yaitu sebanyak $85 \%$. Sedangkan mereka yang memperoleh informasi dari tv/radio/internet sebanyak $10 \%$, brosur/pamphlet sebagai media informasi ke tiga mendapat responden sebanyak 5\%. Hal ini disebabkan karena media ini dirasa tidak efektif bagi masyarakat, terbatas dan hanya ada pada kota-kota tertentu saja.

f. Karakteristik pengunjung krisna fantastic land berdasarkan teman bepergian diketahui bahwa sebagian besar pengunjung yang berkunjung ke Krisna Funtastic Land bersama keluarga yaitu sebesar $47,5 \%$, karena pengunjung yang datang biasanya mengajak rekreasi anakanaknya di saat hari libur. Sedangkan bepergian bersama sahabat atau teman sebanyak $38,8 \%$. Pengunjung yang berkunjung bersama pasangan merupakan jumlah yang terkecil yaitu sebesar 12,5\%.

\subsection{Pemanfaatan Krisna Funtastic Land sebagai sarana rekreasi}

Sesuai dengan data yang telah didapat mengenai pemanfaatan yang dilakukan pengunjung serta motivasi dan karakteristiknya, maka peneliti mencoba untuk mengkolaborasikan antara pemanfaatan dengan motivasi dan karakteristiknya untuk mendapatkan suatu gagasan pengembangan produk yang sesuai dengan motivasi dan karakteristik pengunjung. Berdasarkan poin 4.2 motivasi pengunjung yang datang adalah rekreasi, bersenang-senang atau tamasya, menyalurkan hobi, dan kesehatan serta bertemu orang baru. Sedangkan poin 4.3 karakteristik pengunjung Krisna Funtastic Land mayoritas adalah para remaja dan anak-anak yang sebagian besar berasal dari kota Singaraja sendiri dengan latar belakang pendidikan paling banyak adalah SMA/SMK dan pengunjung mendapatkan informasi mengenai Krisna Funtastic Land dari teman/relasi, namun sayangnya sebagian besar dari pengunjung hanya datang rata-rata sebulan sekali. Jumlah biaya yang dikeluarkan kebanyakan lebih dari Rp. 40.000 pada saat berada dilokasi $\mathrm{KFL}$, lama kunjungan mereka paling banyak antara 2-3 jam, jenis kendaraan mobil yang paling banyak digunakan oleh pengunjung dan sebagian dari pengunjung kebanyakan mengajak keluarga untuk berkunjung ke Krisna Funtastic Land.

Pemanfaatan yang dilakukan oleh pengunjung yang datang ke Krisna Funtastic Land ialah mencoba wahana permainan merupakan kegiatan yang paling digemari oleh pengunjung karena memang wahana permainanlah yang menjadi daya Tarik utama di Krisna Funtastic Land. Makna yang diperoleh pengunjung setelah melakukan kegiatan Leisure and Recreation di Krisna Funtastic land bahwa sebagian besar pengunjung memilih rekreasi sebagai kebutuhan fundamental.

\section{PENUTUP}

\subsection{Simpulan}

Motivasi pengunjung Krisna Funtastic Land, dari hasil pembahasan, dapat disimpulkan bahwa Krisna Funtastic Land saat ini lebih banyak dikunjungi oleh wisatawan lokal dengan berbagai macam motivasi. Jenis motivasi yang paling banyak ditemukan dari 80 orang pengunjung yang dijadikan sample adalah rekreasi dengan jumlah 64 orang, kemudian bersenang-senang 
atau tamasya 16 orang. Karakteristik Pengunjung Krisna Funtastic Land, kelompok umur terbanyak yang mengunjungi Krisna Funtastic Land adalah di bawah 20 tahun yang mayoritasnya mereka remaja yang memiliki lebih banyak waktu luang, pengunjung yang berkunjung ke Krisna Funtastic Land ini mayoritas juga berasal dari kota Singaraja itu sendiri dengan jumlah 70 orang dan 42 orang pengunjung yang menjadi responden adalah perempuan meskipun pengunjung yang berjenis kelamin laki-laki hampir tidak kalah jumlahnya.

Tingkat kunjungan di Krisna Funtastic Land kebanyakan dari pengunjung datang satu kali dalam sebulan dengan jumlah responden 77 orang dari 80 orang yang dijadikan sample, mayoritas 53 orang pengunjung mengeluarkan biaya saat di Krisna Funtastic Land sebesar lebih dari 40.000 rupiah. Sedangkan untuk lamanya kunjungan di Krisna Funtastic Land 74 orang memilih 1-2 jam per hari, jenis kendaraan yang paling banyak digunakan pengunjung adalah sepeda motor yaitu dengan responden sejumlah 53 orang, karena dengan menggunakan sepeda motor dinilai lebih murah den fleksibel. Dan dari data hasil survei menunjukkan bahwa bepergian bersama keluarga merupakan salah satu opsi yang paling banyak dipilih oleh pengunjung dengan jumlah 51 orang. Berdasarkan hasil dari pembahasan mengenai pemanfaatan berdasarkan motivasi dan karakteristik Krisna Funtastic Land terdapat beberapa jenis aktivitas pemanfaatan yang dapat dilakukan yaitu dengan mengoptimalkan atraksi wisata bukan hanya untuk anak-anak saja tapi untuk remaja/dewasa juga, hendaknya pihak pengelola membuat wahana ekstrim khusus untuk remaja/dewasa, sehingga dapat lebih meningkatkan minat berkunjung wisatawan, harga tiket wahana permainan hendaknya dirubah agar lebih ekonomis, memperluas dan memperpanjang rute di wahana naik perahu dayung, tiket masuk dengan tiket permainan hendaknya dijadikan satu,

\subsection{Saran}

Krisna Funtastic Land hendaknya dibuka dari pagi hari agar para pengunjung dapat lebih bebas menentukan waktu. Sebaiknya jenis wahana permainan di Krisna Funtastic Land lebih diperbanyak agar para pengunjung lebih lama berkunjung. Menyediakan wahana permainan yang lebih memacu adrenalin karena pengunjung yang datang kebanyakan remaja dan dewasa. Harga tiket wahana permainan hendaknya dikurangi agar lebih ekonomis. Sebaiknya jangka waktu bermain wahana lebih diperpanjang lagi.

Bagi pihak Krisna Funtastic Land, disarankan lebih memperhatikan Standar Operasional Prosedur (SOP) di setiap wahana permainan demi menjamin keselamatan pengunjung. Peningkatan promosi sangat penting dilakukan agar informasi tentang keberadaan Krisna Funtastic Land banyak yang mengetahui dan juga dapat meningkatkan jumlah pengunjung ke Krisna Funtastic Land.

\section{DAFTAR PUSTAKA}

Ashari, Dinar Ahadin. 2006 "Motivasi, Karakteristik dan Persepsi Wisatawan yang Berkunjung ke Danau Sarangan". Laporan Akhir PS. Pariwisata Universitas Udayana.

Creswell John.W. 2014. Penelitian Kualitatif \& Desain Riset. Yogyakarta: Pustaka. Pelajar.

Deni, Kadek. 2007. "Pemanfaatan Danau Serangan Sebagai Sarana Leisure and Recreation di Kabupaten Magetan Provinsi Jawa Timur". Laporan Akhir PS.Pariwisata Universitas Udayana.

Gunawan, Imam.2013. Metode Penelitian Kualitatif:teori dan praktek.Jakarta:PT. Bumi Aksara.

Haryono,1978, Pariwisata Rekreasi dan Entertainmen, Ilmu Bandung.

Juwita, Vina. 2010. " Pemanfaatan Atlanta Water Park and Playground Sebagai Sarana Leisure and Recreation di Kabupaten Banyuwangi Provinsi Jawa Timur"Laporan Wisata Karya III.Denpasar: Fakultas Pariwisata.Udayana.

Kusmayadi, dan Endar Sugiarti. 2000.Metodologi Penelitian Dalam Bidang Kepariwisataan. Jakarta: Gramedia Pustaka.

Kusmayadi dan Sugiarto, E., 2000, Metodologi Penelitian dalam Bidang. Kepariwisataan, Jakarta: PT. Gramedia Pustaka Utama.

Margono.2004. Metodologi Penelitian Pendidikan. Jakarta:Rineka Cipta.

Moleong. 2012. Metodologi penelitian kualitatif. Bandung: PT.remaja rosdakarya.

Marpaung, 2000. Metodologi penelitian. Jakarta: Gramedia Pustaka.

Permatasari, Shindi Ayu, and I. Gusti Agung Oka Mahagangga. "Studi Komparasi Taman Kota Lumintang Dan Taman Kota Puputan Margarana Niti Mandala Renon Sebagai Sarana Leisure And Recreation." JURNAL DESTINASI PARIWISATA 
Vol. 7 No 1, 2019

Rohman, Fatur. 2004. "Pemanfaatan Pemandian Air Panas Guci Sebagai Sarana Leisure and Recreation di Kabupaten Tegal Jawa Tengah". Laporan Akhir PS.Pariwisata.

Santoso, Singgih. 2014. Statistik Multivariat, Edisi Revisi, Konsep dan Aplikasi dengan SPSS. Penerbit PT. Elex Media Komputindo. Jakarta.

Sugiarto, E., 2000, Metodologi Penelitian dalam Bidang. Kepariwisataan, Jakarta: PT. Gramedia Pustaka Utama.

Sugiyono, 2009, Metode Penelitian Kuantitatif, Kualitatif dan R\&D, Bandung

Sugiyono.2010. Metodologi penelitian kuantitatif,kualitatif dan R\&D (Research and Development).Bandung:Alfabeta

Sugiyono. 2014. Metode Penelitian Pendidikan Pendekatan Kuantitatif, Kualitatif Dan R\&D. Bandung: Alfabeta.

Sutopo (2006). Metodologi Penelitian Kualitatif : Dasar teori dan Terapannya dalam Penelitian Surakarta: Universitas. Sebelas Maret.

Tribe, John. The economics of recreation, leisure and tourism. Routledge, 2015.

Sumber lainnya :

www.krisnafuntasticland.com

https://id.m.wikipedia.org/wiki/Kabupaten_Buleleng 